\title{
ANÁLISE ECONÔMICA DO MILHO EM SUCESSÃO A DIFERENTES ADUBOS VERDES, MANEJOS DO SOLO E DOSES DE NITROGÊNIO
}

\author{
ECONOMIC EVALUATION OF MAIZE IN SUCCESSION TO DIFFERENT \\ GREEN MANURE, SOIL MANAGEMENT AND NITROGEN DOSES
}

\author{
Claudinei KAPPES ${ }^{1}$; Douglas Castilho GITTI' ${ }^{2}$; Orivaldo ARF $^{3}$; \\ João Antônio da Costa ANDRADE ; Maria Aparecida Anselmo TARSITANO \\ 1. Engenheiro Agrônomo, Doutor em Agronomia, Especialidade em Sistemas de Produção, Pesquisador - área de fertilidade do solo, \\ Fundação MT; 2. Engenheiro Agrônomo, Mestrando em Sistemas de Produção - Universidade Estadual Paulista - UNESP, Ilha Solteira, \\ SP, Brasil. gittidouglas@ hotmail.com; 3. Professor, Doutor, Departamento de Fitotecnia, Tecnologia de Alimentos e Sócio economia - \\ UNESP, Ilha Solteira, SP, Brasil; 4. Professor, Doutor, Departamento de Biologia - UNESP, Ilha Solteira, SP, Brasil; 5. . Professora, \\ Doutora, Departamento de Fitotecnia, Tecnologia de Alimentos e Sócio economia de Agronomia - UNESP, Ilha Solteira, SP, Brasil.
}

RESUMO: Tecnologias que aumentam a produtividade das culturas são viáveis quando proporcionam lucratividade ao produtor. O objetivo deste trabalho foi avaliar os custos de produção e a lucratividade do milho irrigado, em diferentes sistemas de produção no cerrado. O trabalho foi conduzido em Selvíria (MS), nos anos 2009/10 e 2010/11. $\mathrm{O}$ delineamento experimental foi disposto em blocos ao acaso com quatro repetições, em esquema misto com faixas e fatorial. Foram estabelecidos 36 tratamentos, sendo três adubos verdes (milheto, crotalária e consórcio milheto + crotalária), três manejos do solo (sistema plantio direto, "grade pesada" + "grade leve" e "escarificador" + "grade leve") e quatro doses de $\mathrm{N}$ em cobertura $\left(0,60,90\right.$ e $\left.120 \mathrm{~kg} \mathrm{ha}^{-1}\right)$. Para análise econômica foram estimados o custo operacional efetivo, a receita bruta obtida pelo produto em função da produtividade dos tratamentos e o valor dos grãos de milho (R\$ $0,417 \mathrm{~kg}^{-1}$ ou $\mathrm{R} \$ 25,00 \mathrm{sc}^{-1}$ ) e a relação receita/custo dos tratamentos. Considerando valores maiores (receita/custo $>1$ ) e menores (receita/custo < 1) como parâmetro na análise de lucratividade, pode-se concluir que o milho no sistema plantio direto obteve maior lucratividade; em sucessão ao milheto lucratividade crescente com o aumento das doses de $\mathrm{N}$, em sucessão a crotalária e na ausência da aplicação do adubo nitrogenado em cobertura obteve a maior lucratividade em relação aos demais tratamentos e em sucessão ao consórcio milheto + crotalária doses de $\mathrm{N}$ em cobertura entre 50 e $55 \mathrm{~kg}$ $\mathrm{ha}^{-1}$ proporcionam maior lucratividade ao cultivo do milho.

PALAVRAS-CHAVE: Zea mays. Crotalaria juncea. Pennisetum glaucum. Lucratividade. Custo de produção.

\section{INTRODUÇÃO}

A produção mundial de milho em 2010 foi de 844,4 milhões de toneladas, sendo os maiores produtores Estados Unidos, China e Brasil, responsáveis por aproximadamente 37,21 e $7 \%$ da produção mundial, respectivamente (FAO, 2012). Estados Unidos e China são países localizados em altas latitudes em relação ao Brasil, favorecendo-os com maiores produtividades. Porém, não só os efeitos ambientais refletem em baixa produtividade do milho dos produtores brasileiros, mas também, a inferioridade tecnológica (FORNASIERI FILHO, 2007) e a ausência de informações economicamente viáveis que amparem os diferentes manejos da cultura em condições tropicais.

O conhecimento do custo de produção dos manejos adotados para a cultura do milho, tais como a adubação verde, o manejo do solo e as doses de $\mathrm{N}$ em cobertura são importantes e necessários, uma vez que fornecem informações para a adoção de diferentes níveis tecnológicos e ampliam o leque de tecnologias mais sustentáveis e lucrativas.
O cultivo do milho em sucessão à crotalária proporciona maior produtividade física e econômica de grãos, comparado ao milho em sucessão ao milheto e ao solo em pousio (SILVA et al., 2007; ANDRIOLI et al., 2008). No entanto, como cobertura vegetal, o milheto é amplamente utilizado para a produção de palha e manutenção do sistema plantio direto, devido à maior oferta de sementes no mercado e o menor preço em relação às demais espécies utilizadas para essa finalidade, principalmente as leguminosas. Além disso, é uma espécie $\mathrm{C}_{4}$, podendo ser mais eficiente do que a crotalária em condições de déficit hídrico, mas semelhantes em produção de palha em condições de irrigação, antecedendo culturas de verão (CAZETTA et al., 2008).

Com o intuito de reduzir o custo da aquisição de sementes utilizadas para cobertura vegetal e manter os benefícios das diferentes espécies vegetais, a consorciação entre espécies de maior e menor valor de sementes pode ser realizada. $\mathrm{Na}$ região de cerrado o milho em sucessão às coberturas vegetais crotalária e o consórcio milheto + crotalária proporcionaram as maiores 
produtividades de grãos em relação à sucessão milheto/milho, como também para a cultura do trigo, em sucessão aos consórcios milheto + guandu e milheto + crotalária (GITTI et al., 2012), inclusive com reduções das doses de $\mathrm{N}$ necessárias em cobertura.

A resposta produtiva das culturas é distinta entre os diferentes manejos do solo, tendo em vista o crescimento radicular e a absorção dos nutrientes pelas plantas, principalmente o N (FIGUEIREDO et al., 2005). O cultivo do milho em sucessão à diferentes adubos verdes e manejos do solo pode proporcionar reduções nas doses de $\mathrm{N}$ em cobertura no milho (SILVA; SOUZA, 2007; KAPPES, 2012), como também, economia e lucratividade ao produtor.

Com base no exposto, as condições benéficas proporcionadas pelos adubos verdes ao milho cultivado em sucessão são descritas na literatura, porém, há carência de informações sobre as vantagens econômicas da utilização dos adubos verdes antecedendo o milho e a possibilidade da redução do fertilizante nitrogenado em cobertura. Assim, o presente trabalho teve como objetivo determinar o custo de produção do milho irrigado na região de cerrado, em sucessão a diferentes adubos verdes, manejos do solo e doses de $\mathrm{N}$ em cobertura.

\section{MATERIAL E MÉTODOS}

O trabalho foi desenvolvido em 2009/11 e 2010/12 na área experimental da UNESP, Campus de Ilha Solteira $\left(20^{\circ} 20^{\prime} \mathrm{S}\right.$ e $\left.51^{\circ} 24^{\prime} \mathrm{W}\right)$, localizada no município de Selvíria (MS), com altitude de 340 m. O clima predominante da região, conforme classificação de Köppen, é do tipo Aw, definido como tropical úmido com estação chuvosa no verão e seca no inverno. A precipitação pluvial média anual é de $1.330 \mathrm{~mm}$, com temperatura do ar média anual de aproximadamente $25^{\circ} \mathrm{C}$ e umidade relativa do ar média anual de 66\% (CENTURION, 1982). O solo da área foi classificado como Latossolo Vermelho distrófico álico e de textura argilosa, o qual foi originalmente ocupado por vegetação de Cerrado e vem sendo explorado por culturas anuais há mais de 26 anos.

Foram estabelecidos 36 tratamentos, com quatro repetições, constituídos pela combinação de três adubos verdes [milheto (Pennisetum glaucum), crotalária (Crotalaria juncea) e milheto + crotalária)], três manejos do solo [sistema plantio direto (SPD), "grade pesada" + "grade leve" ("GP" + "GL") e escarificador + "grade leve" ("E" + "GL")] e quatro doses de Nitrogênio (N) [0 (tratamento sem aplicação de N), 60, 90 e 120 kg ha' ${ }^{1}$ ], utilizando como fonte a ureia.

Antes da semeadura dos adubos verdes, as plantas daninhas presentes na área foram dessecadas com $960 \mathrm{~g} \mathrm{ha}^{-1}$ de glifosato, sendo o herbicida aplicado com pulverizador tratorizado de barras regulado para aplicação de $220 \mathrm{~L} \mathrm{ha}^{-1}$ de calda. A semeadura dos adubos verdes foi realizada mecanicamente em 27/08/2009 e 04/10/2010. Para o milheto e crotalária foram utilizados os espaçamentos de 0,17 e $0,34 \mathrm{~m}$ e quantidade de sementes de 15 e $50 \mathrm{~kg} \mathrm{ha}^{-1}$, respectivamente. No consórcio, o milheto foi semeado em linhas intercalares com a crotalária, portanto, espaçadas de $0,17 \mathrm{~m}$ em ambos os anos.

Aos 63 e 56 dias após a semeadura, para 2009/10 e 2010/11 respectivamente, os adubos verdes foram dessecados com 1.440 e $800 \mathrm{~g} \mathrm{ha}^{-1}$ de glifosato e 2,4-D, sendo o herbicida aplicado com pulverizador tratorizado de barras regulado para 200 $\mathrm{L} \mathrm{ha}^{-1}$ de calda. Não foram realizados quaisquer tipos de adubação mineral e tratamentos fitossanitários das coberturas vegetais. $\mathrm{O}$ fornecimento de água, quando necessário, foi realizado com sistema de irrigação por aspersão do tipo "canhão" hidráulico auto-propelido, levando-se em consideração os dados de precipitação pluvial registrados na Estação Metereológica da Fazenda de Ensino, Pesquisa e Extensão da UNESP.

Cinco dias após a dessecação, os adubos verdes foram manejados com triturador mecânico horizontal (Triton®). Após a fragmentação mecânica dos adubos verdes, foi avaliada a produtividade de massa seca de parte aérea (MSPA). Foram realizadas amostragens ao acaso com quadrante de $0,25 \mathrm{~m}^{2}(0,5 \times 0,5 \mathrm{~m})$ em dois pontos representativos de cada parcela. $\mathrm{O}$ material coletado no quadrante foi submetido à secagem em estufa com renovação e circulação forçada de ar à temperatura de $60 \pm 5^{\circ} \mathrm{C}$, até atingir massa constante. A produtividade de MSPA foi obtida, dessa maneira, pela média aritmética entre os dois pontos amostrados, com os valores médios extrapolados para $\mathrm{kg} \mathrm{ha}^{-1}$.

O solo foi manejado dois dias após os adubos verdes serem fragmentados mecanicamente. O manejo do solo com GP + GL foi realizado com grade de 14 x 32 " na profundidade em torno de 0,2 $m$ e com outra grade de $32 \times 20$ " na profundidade de 0,1 m. O manejo com E + GL foi realizado com implemento escarificador de sete hastes com profundidade de trabalho em torno de $0,35 \mathrm{~m}$ e com grade de 32 x 20" à profundidade aproximada de 0,1 m. O manejo no SPD foi restrito somente a trituração mecânica dos adubos verdes. É oportuno 
ressaltar que nesse sistema, os resíduos das culturas proporcionaram excelente cobertura do solo, com médias de produtividade de massa de matéria seca para os anos 2009/10 e 2010/11 respectivamente de milheto -7.765 e 9.323 , crotalária -10.047 e 14.377 e o consórcio - 9.880 e $12.554 \mathrm{~kg} \mathrm{ha}^{-1}$.

Após o tratamento de sementes de milho (híbrido DKB 350 YG, utilizado em ambas os anos) com 50 e 150 g de imidacloprido e tiodicarbe, respectivamente, para 60.000 sementes, foi realizada a semeadura em 16/11/2009 e 11/12/2010, em espaçamento de $0,90 \mathrm{~m}$ e densidade de semeadura de 5,4 sementes $\mathrm{m}^{-1}$. As parcelas experimentais foram constituídas por seis linhas de $5,0 \mathrm{~m}$ de comprimento, espaçadas de $0,9 \mathrm{~m}$, uma vez que para coleta dos dados foram utilizadas as quatro linhas centrais de cada parcela. $\mathrm{Na}$ avaliação de produtividade do milho, foram utilizadas as duas linhas centrais. A primeira e a sexta linhas foram consideradas bordaduras.

A adubação de semeadura foi de $300 \mathrm{~kg} \mathrm{ha}^{-1}$ de 08-28-16, o controle de plantas daninhas foi realizado com $1.000,100$ e $500 \mathrm{~g} \mathrm{ha}^{-1}$ de atrazine, tembotrione e óleo de soja, respectivamente, para ambos os anos agrícolas, não havendo necessidade de controle de pragas. A adubação de cobertura foi realizada quando $50 \%$ das plantas apresentaram cinco folhas expandidas em ambos os anos. No ano 2009/10, o florescimento e a colheita do milho ocorreram aos 50 e 137 dias após a emergência (DAE), e em 2010/11 aos 50 e 125 DAE.

A produtividade do milho foi obtida a partir da debulha e pesagem dos grãos oriundos das espigas colhidas na área útil das parcelas, sendo os valores extrapolados para $\mathrm{kg} \mathrm{ha}^{-1}$ e corrigidos para $13 \%$ de umidade (b.u.).

O custo operacional efetivo (COE) da produção de milho para os tratamentos foram estimados pela soma dos valores das operações manuais, mecanizadas e insumos utilizados, extrapolados para hectare, sendo consideradas apenas as despesas diretas de custeio (MATSUNAGA et al., 1976). Não foram calculadas as despesas com encargos financeiros, outras despesas e depreciações. O preço das operações mecanizadas foi calculado com base no Agrianual (2012), referente aos custos de hora máquina de tratores e implementos utilizados. Para as operações manuais consideraram-se os valores vigentes em maio de 2012 na região noroeste paulista. Os preços dos insumos agrícolas foram obtidos no Instituto de Economia Agrícola - IEA (2012). A produtividade dos tratamentos auxiliou na obtenção da receita bruta, multiplicando-se o preço do milho em grão $\left(\mathrm{R} \$ 0,417 \mathrm{~kg}^{-1}\right)$ de fevereiro de 2012 obtido no IEA. Para avaliação econômica de cada tratamento foi utilizada a relação receita/custo de cada tratamento. Foram consideradas como lucrativas, as interações significativas pelo teste $\mathrm{F}$ entre adubos verdes, manejos do solo e doses de $\mathrm{N}$ que proporcionaram relação receita/custo superior a 1,0 .

\section{RESULTADOS E DISCUSSÃO}

Os valores das operações mecanizadas, manuais e dos insumos utilizados para o cálculo dos custos operacionais do milho em sucessão aos adubos verdes, manejos do solo e doses de $\mathrm{N}$ estão apresentados na Tabela 1.

Tabela 1. Custos das operações e insumos utilizados na produção do milho. Selvíria, MS, 2012.

\begin{tabular}{|c|c|c|c|c|}
\hline Descrição & Especificação & Quantidade & $\begin{array}{r}\text { Valor } \\
\text { unitário }\end{array}$ & Total (R\$) \\
\hline \multicolumn{5}{|l|}{ A. OPERAÇÕES MECANIZADAS } \\
\hline Escarificação & $\mathrm{HM}^{1}$ & 0,70 & 97,69 & 68,383 \\
\hline Grade leve & HM & 0,50 & 82,07 & 41,035 \\
\hline Grade pesada & HM & 0,70 & 116,94 & 81,858 \\
\hline Pulverização & HM & 0,15 & 54,63 & 8,19 \\
\hline Semeadura dos adubos verdes & HM & 1,60 & 103,67 & 165,87 \\
\hline Triton ${ }^{\circledR}$ - Manejo dos adubos verdes & HM & 0,95 & 55,38 & 52,61 \\
\hline Semeadura do milho & HM & 1,30 & 103,67 & 134,77 \\
\hline Adubação nitrogenada de cobertura - Milho & HM & 0,60 & 55,38 & 33,23 \\
\hline Irrigação - Milho & $\mathrm{R} \$ \mathrm{~mm}^{-1}$ & 150,00 & 2,00 & 300,00 \\
\hline Colheita - Milho & ha & 1,00 & 134,00 & 134,00 \\
\hline \multicolumn{5}{|l|}{ B. OPERAÇÕES MANUAIS } \\
\hline Semeadura & $\mathrm{HD}^{2}$ & 0,20 & 35,00 & 7,00 \\
\hline Tratos Culturais & HD & 0,20 & 35,00 & 7,00 \\
\hline Colheita & $\mathrm{HD}$ & 0,20 & 35,00 & 7,00 \\
\hline
\end{tabular}


Adubo de semeadura 08-28-16

Ureia (45\% de N) $-60 \mathrm{~kg} \mathrm{ha}^{-1} \mathrm{~N}$

Ureia (45\% de N) $-90 \mathrm{~kg} \mathrm{ha}^{-1} \mathrm{~N}$

Ureia (45\% de N) - $120 \mathrm{~kg} \mathrm{ha}^{-1} \mathrm{~N}$

Gliz 480 - Glifosato $\left(480 \mathrm{~g} \mathrm{~L}^{-1}\right)$

Gliz 480 - Glifosato $\left(480 \mathrm{~g} \mathrm{~L}^{-1}\right)$

DMA 806 BR - 2,4 D (806 $\left.\mathrm{g} \mathrm{L}^{-1}\right)$

Gesaprim 500 - Atrazine $\left(500 \mathrm{~g} \mathrm{~L}^{-1}\right)$

Soberan - Tembotrione $\left(420 \mathrm{~g} \mathrm{~L}^{-1}\right)$

Cropstar - Imidacloprido + Tiodicarbe

$\mathrm{L}^{-1}+450 \mathrm{~g} \mathrm{~L}^{-1}$ )

Milheto BRS 1501 (solteiro)

Crotalária juncea (solteiro e consórcio)

Milheto BRS 1501 (consórcio)

DKB 350 YG

${ }^{1} \mathrm{HM}$ - hora máquina. ${ }^{2} \mathrm{HD}$ - homem dia.

O custo de produção do milho, sem considerar o valor das sementes dos adubos verdes e da operação de aplicação do adubo nitrogenado em cobertura nas doses de $\mathrm{N}$ (ureia) corresponde a $\mathrm{R} \$$ $1.735,72 \mathrm{ha}^{-1}$. Isso foi calculado pela soma das operações mecanizadas [três pulverizações: (i) dessecação da área experimental para semeadura dos adubos verdes; (ii) dessecação dos adubos verdes e; (iii) aplicação dos herbicidas para controle de plantas daninhas no milho, semeadura dos adubos verdes, fragmentação dos adubos verdes Triton e, semeadura, irrigação e colheita do milho], operações manuais (semeadura, tratos culturais e colheita do milho) e insumos (adubo de semeadura, herbicidas glifosato (5 L do produto comercial), 2,4 $\mathrm{D}$, atrazina, soberan, inseticida cropstar para tratamento de sementes e sementes do híbrido DKB $350 \mathrm{YG}]$.

A aquisição das sementes de milheto e crotalária para os cultivos solteiros oneraram os custos de produção do milho em $\mathrm{R} \$ 22,50$ e $\mathrm{R} \$$ 325,00 respectivamente, e para o consórcio em $\mathrm{R} \$$ 336,25. A capacidade de produção de grãos do milheto (BRS 1501) e crotalária (Crotalaria juncea) é baixa, sendo em média de 900 (GERALDO et al., 2002) e $612 \mathrm{~kg} \mathrm{ha}^{-1}$ (DOURADO et al., 2001) respectivamente, aumentando o preço das sementes em períodos de alta demanda pelos produtores.

Para a crotalária, a maior densidade de semeadura utilizada $\left(50 \mathrm{~kg} \mathrm{ha}^{-1}\right)$ em relação ao milheto $\left(15 \mathrm{~kg} \mathrm{ha}^{-1}\right)$ e o alto custo das sementes onerarou mais o custo de produção do milho. A operação de aplicação do adubo nitrogenado em cobertura, o custo de produção do milho foi onerado em $\mathrm{R} \$ 33,23$. As quantidades de ureia que correspondentes às doses de $60,90 \mathrm{e} 120 \mathrm{~kg} \mathrm{ha}^{-1} \mathrm{de}$ $\mathrm{N}$, oneraram a produção do milho em $\mathrm{R} \$ 225,28$; 338,00 e 450,55 respectivamente.

\begin{tabular}{rrr}
0,30 & 1.200 & 360,00 \\
133,30 & 1,69 & 225,28 \\
200,00 & 1,69 & 338,00 \\
266,60 & 1,69 & 450,55 \\
2,00 & 6,45 & 12,90 \\
3,00 & 6,45 & 19,35 \\
1,00 & 12,45 & 12,45 \\
2,00 & 8,28 & 16,56 \\
0,24 & 301,01 & 72,24 \\
& & \\
0,33 & 180,00 & 59,40 \\
15,00 & 1,50 & 22,50 \\
50,0 & 6,50 & 325,00 \\
7,50 & 1,50 & 11,25 \\
1,00 & 350 & 350,00 \\
\hline
\end{tabular}

Os maiores custos de produção do milho foram proporcionados no sistema em sucessão ao consórcio milheto + crotalária, manejo do solo com "GP" + "GL" e na maior dose de N em cobertura $\left(120 \mathrm{~kg} \mathrm{ha}^{-1}\right)$ (Tabela 2). Em relação aos adubos verdes, o milheto + crotalária acrescentou o maior valor ao custo de produção do milho na aquisição das sementes $(\mathrm{R} \$ 325,00+11,25)$, pois a quantidade de sementes de crotalária foi igual ao seu cultivo solteiro $(50 \mathrm{~kg})$ mais metade da quantidade de sementes utilizada no cultivo solteiro do milheto (7,5 kg). Quanto aos manejos do solo, as operações com "GP" (R\$ 81,86) e "E" (R\$ 68,39) oneraram o custo de produção do milho com preparo do solo, mais a operação com a "GL" (R\$ 41,03), comum aos dois preparos do solo ("GP" e "GL"). A "GP" apresentou menor eficiência de campo, devido à menor largura de trabalho em relação ao "E", levando a um maior gasto de tempo por hectare e onerando esta operação em aproximadamente $R \$$ 14,00 a mais que o " $E$ ".

A receita de cada tratamento foi obtida considerando as produtividades (Tabela 3) e o preço de $\mathrm{R} \$ 0,417 \mathrm{~kg}^{-1}$ de grãos $\left(\mathrm{R} \$ 25,00 \mathrm{sc}^{-1}\right)$ obtido em fevereiro de 2012 pelo IEA. A partir da receita e do custo de produção (Tabela 2) foi analisada a viabilidade econômica dos sistemas de produção do milho pela relação receita/custo (Tabela 4).

Valores acima de 1 (receita/custo $>1,0$ ) ou inferiores (receita/custo $<1,0$ ), indicam que houve lucratividade ou prejuízo, respectivamente. Para o ano 2009/10, o preparo do solo com "GP" + "GL", adubos verdes em cultivo solteiro de crotalária e em consórcio (milheto + crotalária) proporcionaram valores da relação receita/custo de 0,98 e 0,99 , respectivamente, ambos na dose de $\mathrm{N}$ em cobertura de $90 \mathrm{~kg} \mathrm{ha}^{-1}$, sem influência na produtividade que proporcionasse aumento no lucro. Os maiores 
valores $(1,60$ e 1,58) foram obtidos com o cultivo do milho em sucessão ao manejo do solo em SPD, adubos verdes crotalária e consórcio (milheto + crotalária) na ausência da aplicação do adubo nitrogenado, com lucratividades aproximadas de 60 e $58 \%$ sobre os custos de produção de $\mathrm{R} \$ 2.061$ e 2.072 , respectivamente.

Tabela 2. Custos operacionais efetivos (COE) do milho em sucessão aos adubos verdes, manejos do solo e doses de N para 2009/10 e 2010/11. Selvíria (MS), 2012.

\begin{tabular}{|c|c|c|c|c|}
\hline Tratamentos & 0 $\mathrm{kg} \mathrm{ha}^{-1} \mathrm{~N}$ & $60 \mathrm{~kg} \mathrm{ha}^{-1} \mathrm{~N}$ & $90 \mathrm{~kg} \mathrm{ha}^{-1} \mathrm{~N}$ & $120 \mathrm{~kg} \mathrm{ha}^{-1} \mathrm{~N}$ \\
\hline SPD & 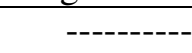 & --------------. & - & ------- \\
\hline Milheto & 1.758 & 2.017 & 2.129 & 2.242 \\
\hline Crotalária & 2.061 & 2.319 & 2.432 & 2.545 \\
\hline Consórcio & 2.072 & 2.330 & 2.443 & 2.556 \\
\hline \multicolumn{5}{|l|}{$\mathbf{G P}+\mathbf{G L}$} \\
\hline Milheto & 1.881 & 2.140 & 2.252 & 2.365 \\
\hline Crotalária & 2.184 & 2.442 & 2.555 & 2.667 \\
\hline Consórcio & 2.195 & 2.453 & 2.566 & 2.679 \\
\hline \multicolumn{5}{|l|}{$\mathbf{E}+\mathbf{G L}$} \\
\hline Milheto & 1.868 & 2.126 & 2.239 & 2.351 \\
\hline Crotalária & 2.170 & 2.429 & 2.541 & 2.654 \\
\hline Consórcio & 2.181 & 2.440 & 2.553 & 2.665 \\
\hline
\end{tabular}

Tabela 3. Produtividade do milho nas safras 2009/10 e 2010/11 em sucessão aos adubos verdes, manejos do solo e doses de N. Selvíria (MS), 2012.

\begin{tabular}{|c|c|c|c|c|c|c|c|c|}
\hline \multirow{2}{*}{ Tratamentos } & \multicolumn{2}{|c|}{0 kg ha $^{-1} \mathrm{~N}$} & \multicolumn{2}{|c|}{$60 \mathrm{~kg} \mathrm{ha}^{-1} \mathrm{~N}$} & \multicolumn{2}{|c|}{$90 \mathrm{~kg} \mathrm{ha}^{-1} \mathrm{~N}$} & \multicolumn{2}{|c|}{$120 \mathrm{~kg} \mathrm{ha}^{-1} \mathrm{~N}$} \\
\hline & $2009 / 10$ & 2010/11 & $2009 / 10$ & 2010/11 & $2009 / 10$ & 2010/11 & $2009 / 10$ & 2010/11 \\
\hline SPD & \multicolumn{8}{|c|}{ 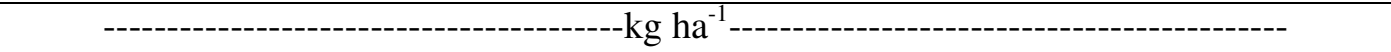 } \\
\hline Milheto & 4.314 & 5.375 & 5.293 & 6.640 & 5.724 & 7.287 & 6.616 & 7.789 \\
\hline Crotalária & 5.904 & 7.889 & 6.833 & 8.297 & 6.607 & 8.367 & 6.905 & 8.275 \\
\hline Consórcio & 5.845 & 7.849 & 6.281 & 8.098 & 7.237 & 8.616 & 6.679 & 8.616 \\
\hline $\mathbf{G P}+\mathbf{G L}$ & & & & & & & & \\
\hline Milheto & 4.648 & 5.290 & 5.335 & 6.556 & 6.167 & 7.586 & 6.457 & 8.381 \\
\hline Crotalária & 5.603 & 7.197 & 6.953 & 7.789 & 6.010 & 7.881 & 6.465 & 8.385 \\
\hline Consórcio & 5.307 & 6.871 & 6.491 & 8.000 & 6.115 & 7.802 & 6.474 & 8.716 \\
\hline $\mathbf{E}+\mathbf{G L}$ & & & & & & & & \\
\hline Milheto & 4.584 & 4.988 & 5.447 & 7.287 & 5.847 & 7.099 & 5.977 & 7.887 \\
\hline Crotalária & 6.317 & 6.978 & 6.333 & 7.786 & 6.499 & 8.311 & 6.773 & 8.465 \\
\hline Consórcio & 5.709 & 5.994 & 6.440 & 7.102 & 6.480 & 8.055 & 6.643 & 7.961 \\
\hline
\end{tabular}

Tabela 4. Receita/custo do milho nas safras 2009/10 e 2010/11 em sucessão aos adubos verdes, manejos do solo e doses de N. Selvíria (MS), 2012.

\begin{tabular}{|c|c|c|c|c|c|c|c|c|}
\hline \multirow{2}{*}{ Tratamentos } & \multicolumn{2}{|c|}{$0 \mathrm{~kg} \mathrm{ha}^{-1} \mathrm{~N}$} & \multicolumn{2}{|c|}{$60 \mathrm{~kg} \mathrm{ha}^{-1} \mathrm{~N}$} & \multicolumn{2}{|c|}{$90 \mathrm{~kg} \mathrm{ha}^{-1} \mathrm{~N}$} & \multicolumn{2}{|c|}{$120 \mathrm{~kg} \mathrm{ha}^{-1} \mathrm{~N}$} \\
\hline & $2009 / 10$ & $2010 / 11$ & $2009 / 10$ & 2010/11 & $2009 / 10$ & $2010 / 11$ & $2009 / 10$ & $2010 / 11$ \\
\hline \multicolumn{9}{|l|}{ SPD } \\
\hline Milheto & 1,02 & 1,27 & 1,09 & 1,37 & 1,12 & 1,43 & 1,23 & 1,45 \\
\hline Crotalária & 1,19 & 1,60 & 1,23 & 1,49 & 1,13 & 1,43 & 1,13 & 1,36 \\
\hline Consórcio & 1,18 & 1,58 & 1,12 & 1,45 & 1,23 & 1,47 & 1,09 & 1,40 \\
\hline \multicolumn{9}{|l|}{ GP + GL } \\
\hline Milheto & 1,03 & 1,17 & 1,04 & 1,28 & 1,14 & 1,40 & 1,14 & 1,48 \\
\hline Crotalária & 1,07 & 1,37 & 1,19 & 1,33 & 0,98 & 1,29 & 1,01 & 1,31 \\
\hline Consórcio & 1,01 & 1,30 & 1,10 & 1,36 & 0,99 & 1,27 & 1,01 & 1,36 \\
\hline \multicolumn{9}{|l|}{$\mathbf{E}+\mathbf{G L}$} \\
\hline Milheto & 1,02 & 1,11 & 1,07 & 1,43 & 1,09 & 1,32 & 1,06 & 1,40 \\
\hline Crotalária & 1,21 & 1,34 & 1,09 & 1,34 & 1,07 & 1,36 & 1,06 & 1,33 \\
\hline Consórcio & 1,09 & 1,14 & 1,10 & 1,21 & 1,06 & 1,31 & 1,04 & 1,24 \\
\hline
\end{tabular}


A comparação estatística dos valores da relação benefício/custo (Tabela 5), indica diferenças significativas para os manejos do solo em 2009/10 e interações significativas entre os adubos verdes e manejos do solo em 2010/11 e, adubos verdes e doses de $\mathrm{N}$ em cobertura em ambos os anos.

Tabela 5. Valores do teste F da relação receita/custo da cultura do milho em 2009/10 e 2010/11. Selvíria (MS), 2012.

\begin{tabular}{lcc}
\hline Teste $\mathbf{F}$ & $\mathbf{2 0 0 9 / 1 0}$ & $\mathbf{2 0 1 0 / 1 1}$ \\
\hline Adubo verde (A) & 1,22 & 1,33 \\
Manejo do solo (M) & $10,40^{* *}$ & $17,40^{* *}$ \\
Dose de N (D) & 0,62 & $1,11^{*}$ \\
$A^{*} \mathrm{M}$ & 1,20 & $2,45^{* *}$ \\
$A^{*} \mathrm{D}$ & $3,78^{*}$ & $4,67^{* *}$ \\
$\mathrm{M}^{*} \mathrm{D}$ & 0,89 & 1,98 \\
$\mathrm{~A} * \mathrm{M} * \mathrm{D}$ & 1,05 & 0,81 \\
\hline $\mathbf{C V}(\boldsymbol{\%})$ & $\mathbf{9}$ & $\mathbf{9}$ \\
\hline
\end{tabular}

$\mathrm{e}^{*}$ - significativo pelo teste $\mathrm{F}$ a 1 e $5 \%$ de probabilidade, respectivamente.

Além dos efeitos benéficos ao meio ambiente, o SPD é economicamente viável em relação aos manejos do solo com "GP" e "E". Os valores da relação receita/custo de 2009/10 para os manejos do solo SPD, "GP" + "GL" e "E" + "GL" foram de 1,15; 1,06 e 1,08 respectivamente, onde $\mathrm{o}$ SPD apresentou lucratividade (15\%) superior e significativa em relação aos demais manejos do solo, que apresentaram valores semelhantes. Resultados semelhante foram obtidos por Santos et al. (2004) que encontraram maior lucratividade com os manejos do solo sem mobilização (SPD) e cultivo mínimo (modelo JMAD-7 com rolo compactador laminar). Kaneko et al. (2010) também observaram maior lucratividade para o SPD, evidenciando o efeito favorável desta prática aos produtores.
Quanto ao ano 2010/11 (Figura 1), a maior lucratividade do milho em SPD foi evidente em sucessão a crotalária (54\%) e ao consórcio (55\%). A maior disponibilidade de $\mathrm{N}$ pela crotalária (solteira ou consorciada), devido menor relação $\mathrm{C} / \mathrm{N}$, contribuiu para o aumento de produtividade do milho em SPD, além dos benefícios biológicos (OLIVEIRA et al., 2008) e físicos (ANDRADE et al., 2009) ao solo, que podem favorecer a produtividade do milho. A competição por $\mathrm{N}$ entre os microrganismos decompositores da palha e o milho pode justificar os menores valores da relação receita/custo com os manejos do solo com "GP" (39\% após crotalária e 38\% após consórcio) e "E" (40\% após crotalária e $29 \%$ após consórcio) além do maior custo, onerado pelas operações mecanizadas de preparo do solo.

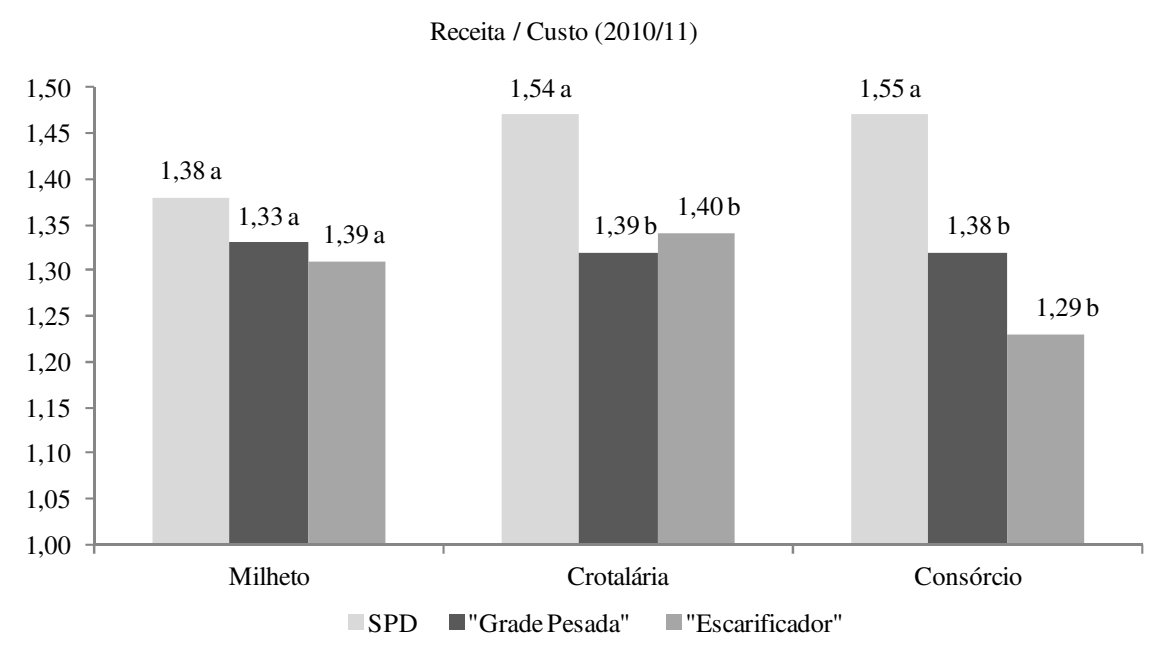

Figura 1. Relação receita/custo do milho em sucessão aos adubos verdes e manejos do solo em 2010/11. Selvíria (MS), 2012. Valores seguidos por letras iguais não diferem pelo teste de Tukey a 5\% de probabilidade. 
A importância do nitrogênio para a cultura do milho, como também para outras gramíneas de importância econômica é indiscutível. Entre as linhas de pesquisas genéticas do milho, o interesse em selecionar cultivares com alta eficiência no uso do nitrogênio, segundo DoVale et al. (2012), será um dos grandes desafios para os próximos anos. Fontes de liberação lenta de nitrogênio, ou que contenham inibidores de nitrificação com o intuito de reduzir perdas de por volatilização e lixiviação, também são tecnologias relacionadas a este importante nutriente para as plantas (SORATTO et al., 2011).

Âs interações entre adubos verdes e doses de $\mathrm{N}$ foram semelhantes para ambos os anos avaliados (Figura 2, a e b).

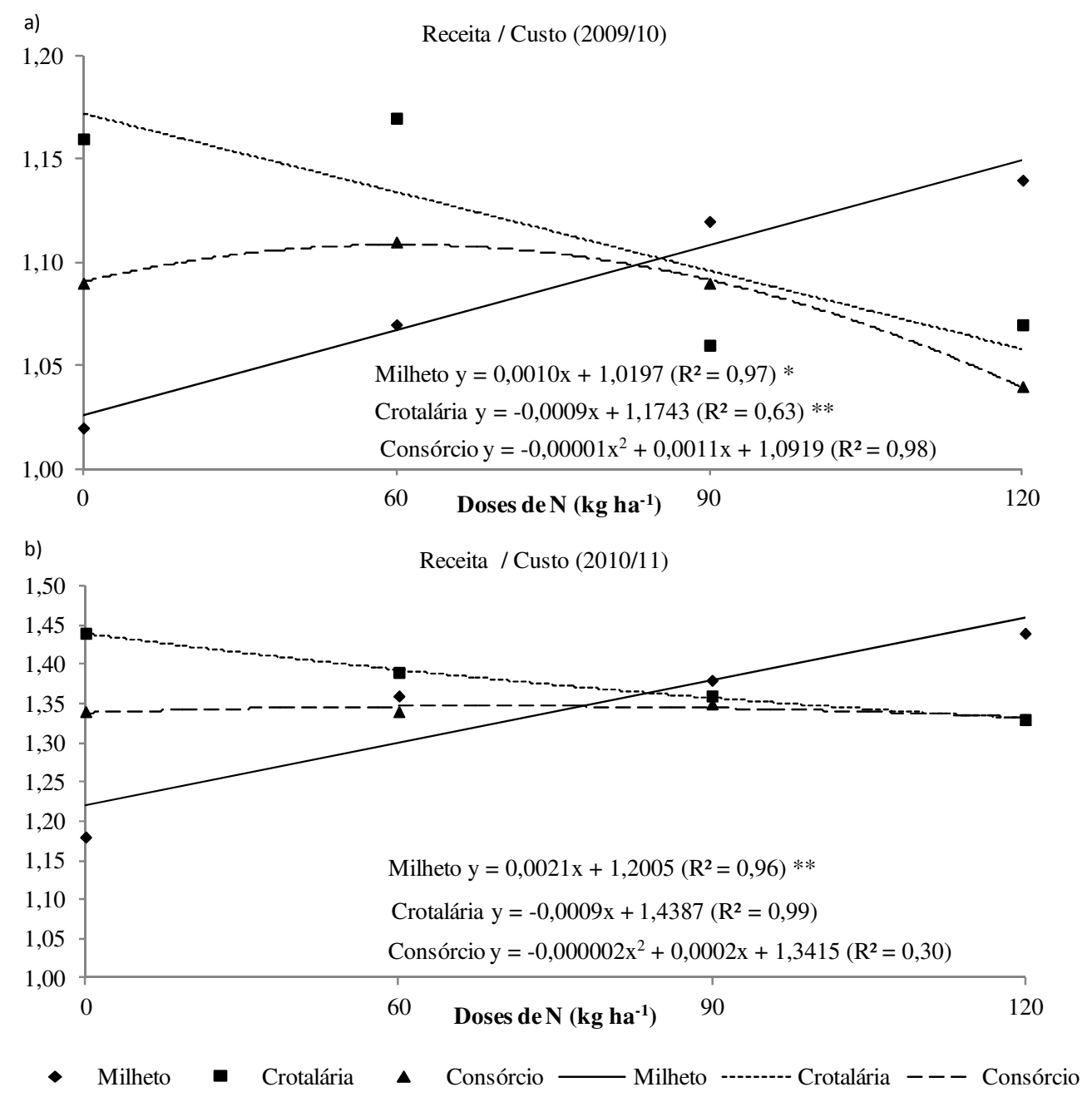

Figura 2. Relação receita/custo do milho em sucessão aos adubos verdes e doses de $\mathrm{N}$ em cobertura em 2009/10 (a) e 2010/11 (b). Selvíria (MS), 2012. ${ }^{* *}$ e ${ }^{*}$ - significativo pelo teste F a 1 e $5 \%$ de probabilidade, respectivamente.

Em sucessão ao milheto, o incremento das doses de $\mathrm{N}$ em cobertura no milho proporcionou aumento linear de lucratividade ao investimento. Para o ano 2009/10, a cada $10 \mathrm{~kg} \mathrm{ha}^{-1}$ de $\mathrm{N}$ aplicado em cobertura houve aumento da relação receita/custo $1 \%$ no cultivo do milho em sucessão ao milheto. No ano 2010/11, o incremento foi duas vezes maior $(2,1 \%)$. Em sucessão à crotalária houve efeito contrário ao observado com milheto, tanto em 2009/10 como 2010/11. Porém, na ausência fertilizante nitrogenado e na dose $60 \mathrm{~kg} \mathrm{ha}^{-1}$ de $\mathrm{N}$, foram obtidos os maiores valores da relação receita/custo $(1,16$ e 1,44$)$ em relação ao milheto e o consórcio. A resposta divergente ao aumento das doses de $\mathrm{N}$ pela crotalária e milheto deve-se ao fato da primeira fornecer $\mathrm{N}$ ao solo via fixação. $\mathrm{O}$ milheto não fornece $\mathrm{N}$ como a crotalária e a resposta positiva da produtividade com o aumento das doses de $\mathrm{N}$ compensa o aumento do custo com essa prática. 
Silva et al. (2007) mencionaram que para produtores de milho que utilizam média tecnologia, a crotalária pode substituir integralmente a fonte de $\mathrm{N}$ inorgânica. Entretanto, a maior parte do $\mathrm{N}$ dos resíduos vegetais não é absorvida pelo milho (SILVA et al., 2008), assim, como verificado por Kaneko et al. (2010), pois as reservas de $\mathrm{N}$ do solo vão se esgotando, à medida em que ocorre a extração do nutriente, caso o mesmo não seja reposto ao solo, comprometendo a produtividade das culturas, ao longo do tempo. Considerando o teor de $\mathrm{N}$ absorvido do solo e exportado pelos grãos de $12,03 \mathrm{~g} \mathrm{~kg}^{-1}$ (sem aplicação de N) (DUETE et al., 2009), pode-se estimar a dose de $\mathrm{N}$ em cobertura no milho em sucessão a crotalária que atendesse a exportação de $\mathrm{N}$ nos grãos, não exaurindo esse nutriente do solo.

Com as produtividades médias respectivas de 6.092 e $7.541 \mathrm{~kg} \mathrm{ha}^{-1}$ em 2009/10 e 2010/11, estimaram-se as doses de $\mathrm{N}$ de aproximadamente 73 e $91 \mathrm{~kg} \mathrm{ha}^{-1}$ para atender a exportação de $\mathrm{N}$ nos grãos, e pelas equações lineares referentes à crotalária, obtiveram-se os valores da relação receita/custo de 1,11 e 1,36, respectivamente. Assim, para o cultivo do milho em sucessão a crotalária, o valor de 1,2\% (comum aos dois anos de avaliação), obtido pela relação entre as doses de $\mathrm{N}$ estimadas para atender a exportação de $\mathrm{N}$ nos grãos e as produtividades médias de 2009/10 e 2010/11, talvez possa ser utilizado. Esse valor $(1,2 \%)$ se aproxima à dose de $\mathrm{N}$ de $60 \mathrm{~kg} \mathrm{ha}^{-1}$ em cobertura, recomendada por Raij e Cantarella (1997) para a produtividade esperada entre 6.000 e $8.000 \mathrm{~kg} \mathrm{ha}^{-1}$ de grãos, para a classe de média resposta ao $\mathrm{N}$, referente às semeaduras esporádicas de leguminosas. No entanto, mais pesquisas devem ser realizadas, tendo em vista a importância desse nutriente às plantas e sua relevância no custo de produção do milho.

Em sucessão ao consórcio, o milho apresentou maiores valores da relação receita/custo $(1,12$ e 1,34$)$ com a estimativa das doses 55 e $50 \mathrm{~kg}$ ha $^{-1}$ de N para 2009/10 e 2010/11, respectivamente. Entre os adubos verdes, o consórcio apresentou o maior custo com aquisição das sementes de crotalária e milheto, reduzindo a relação receita/custo. Consorciar culturas para produção de palha é interessante e lucrativa, porém, pode-se reduzir a quantidade de sementes da crotalária pela metade, como foi realizado para o milheto. Trabalhando com a cultura do trigo, Gitti et al. (2012) obtiveram maiores lucratividades cultivandoo em sucessão aos consórcios de adubos verdes milheto + guandu e milheto + crotalária de primavera, com reduções das doses de $\mathrm{N}$ em cobertura na mistura de $50 \%$ das quantidades de sementes utilizadas pelos adubos verdes em cultivos solteiros.

A possibilidade de aumento de produtividade do milho em sucessão à crotalária é evidente. Porém, deve-se reduzir a dose de $\mathrm{N}$ em cobertura (SILVA; SOUZA, 2007) para compensar o alto investimento na compra de sementes dessa espécie. É interessante lembrar que, além da disponibilidade de $\mathrm{N}$, a crotalária apresenta outras características pertinentes à espécie que estão inclusas no valor das sementes, principalmente no controle de alguns nematóides e sistema radicular agressivo, podendo reduzir a compactação do solo e contribuir para o aumento da produtividade do milho e para outras culturas utilizadas em rotação nos sistemas de produção.

\section{CONCLUSÕES}

O SPD foi o manejo do solo que proporcionou maior retorno econômico ao milho irrigado.

O milho em sucessão ao milheto proporcionou lucratividade crescente com o aumento das doses de $\mathrm{N}$ em cobertura até a dose de $120 \mathrm{~kg} \mathrm{ha}^{-1}$ de N.

Em sucessão, a crotalária, e na ausência da aplicação do adubo nitrogenado em cobertura, o cultivo do milho apresentou a maior lucratividade em relação aos demais tratamentos avaliados, e considerando a exportação de $\mathrm{N}$ pelos grãos, estimou-se a dose de $\mathrm{N}$ em cobertura de 1,2\% da produtividade esperada que proporcione a maior lucratividade.

Em sucessão ao consórcio milheto + crotalária, a estimativa das doses de $\mathrm{N}$ em cobertura entre 50 e $55 \mathrm{~kg} \mathrm{ha}^{-1}$ proporcionam maior lucratividade ao cultivo do milho.

ABSTRACT: Technologies that increase crop yields are possible when providing profitability to the producer. The objective of this study was to evaluate production costs and profitability of maize in production systems in Cerrado. The study was conducted in Selvíria (Mato Grosso do Sul State), Brazil, in the years 2009/10 and 2010/11. The experiment was arranged in randomized blocks with four replications in factorial and mixed with tracks. We established 36 treatments, three green manures (Pennisetum glaucum, Crotalaria juncea and intercropping Pennisetum glaucum + Crotalaria juncea), three soil management practices (no-tillage system, "heavy disking" + "levelling disking" and "chisel 
plow" + "levelling disking") and four doses of $\mathrm{N}\left(0,60,90\right.$ and $\left.120 \mathrm{~kg} \mathrm{ha}^{-1}\right)$. For economic analysis were estimated operational cost, the gross revenue obtained by the product of the productivity of the treatments and the value of corn (R\$ $0,417 \mathrm{~kg}$ or $\mathrm{R} \$ 25,00 \mathrm{sc}^{-1}$ ) and the ratio revenue / cost of treatment. Whereas higher values (revenue/cost $\left.>1\right)$ and lower (revenue/cost ratio $<1$ ) as a parameter in the analysis of profitability, it can be concluded that corn under no-tillage had the highest profitability in succession to Pennisetum glaucum growing profitability with increasing $\mathrm{N}$ rates, in succession to Crotalaria juncea and in the absence of nitrogen application on the coverage achieved higher profitability compared to other treatments and in succession to the consortium Pennisetum glaucum + Crotalaria juncea doses of $\mathrm{N}$ was between 50 and $55 \mathrm{~kg} \mathrm{ha}^{-1}$ offer greater profitability to the cultivation of corn.

KEYWORDS: Zea mays. Crotalaria juncea. Pennisetum glaucum. Profitability. Cost of production.

\section{REFERÊNCIAS}

ANDRADE, R. S.; STONE, L. F.; SILVEIRA, P. M. Culturas de cobertura e qualidade física de um Latossolo em plantio direto. Revista Brasileira de Engenharia Agrícola e Ambiental, Campina Grande, v. 13, n. 4, p. 411-418, 2009.

ANDRIOLI, I.; BEUTLER, A. N.; CENTURION, J. F.; ANDRIOLI, F. F.; COUTINHO, E. L. M. Produção de milho em plantio direto com adubação nitrogenada e cobertura do solo na pré-safra. Revista Brasileira de Ciência do Solo, Viçosa, v. 32, p. 1691-1698, 2008.

ANUÁRIO DA AGRICULTURA BRASILEIRA - AGRIANUAL. iFNP Consultoria \& Comercio; M \& S Mendes \& Scotoni. São Paulo, Editora Agors, 2012. 482p.

CAZETTA, D. A.; ARF, O.; BUZETTI, S.; SÁ, M. E.; RODRIGUES, R. A. F. Desempenho do arroz de terras altas com a aplicação de doses de nitrogênio e em sucessão às culturas de cobertura do solo em sistema de plantio direto. Bragantia, Campinas, v. 67, n. 2, p. 471-479, 2008. http://dx.doi.org/10.1590/S0006-87052008000200023

CENTURION, J. F. Balanço hídrico da região de Ilha Solteira. Científica, Jaboticabal, v. 10, n. 1, p. 57-61, 1982.

DOURADO, M. C.; SILVA, T. R. B.; BOLONHEZI, A. C. Matéria seca e produção de grãos de Crotalaria juncea L. submetida à poda e adubação fosfatada. Scientia Agricola, Piracicaba, v. 58, n. 2, p. 287-293, 2001.

DOVALE, J. C.; FRITSCHE-NETO, R.; BERMUDEZ, F.; MIRANDA, G. V. Efeitos gênicos de caracteres associados à eficiência no uso de nitrogênio em milho. Pesquisa Agropecuária Brasileira, Brasília, v. 47, n. 3, p. 385-392, 2012. http://dx.doi.org/10.1590/S0100-204X2012000300010

DUETE, R. R. C.; MURAOKA, T.; SILVA, E. C.; AMBROSANO, E. J.; TRIVELIN, P. C. O. Acúmulo de nitrogênio $\left({ }^{15} \mathrm{~N}\right)$ pelos grãos de milho em função da fonte nitrogenada em latossolo vermelho. Bragantia, Campinas, v. 68, n. 2, p. 463-472, 2009. http://dx.doi.org/10.1590/S0006-87052009000200021

FIGUEIREDO, C. C.; RESCK, D. V. S.; GOMES, A. C.; URQUIAGA, S. Sistemas de manejo na absorção de nitrogênio pelo milho em um Latossolo Vermelho no Cerrado. Pesquisa Agropecuária Brasileira, Brasília, v. 40, n. 3, p. 279-287, 2005. http://dx.doi.org/10.1590/S0100-204X2005000300012

FOOD AND AGRICULTURE ORGANIZATION OF THE UNITED NATIONS - FAO. FAOSTAT Production - Crops. Disponível em: < http://faostat.fao.org/site/567/default.aspx\#ancor>. Acesso em: 10 jul. 2012.

FORNASIERI FILHO, D. Manual da cultura do milho. Jaboticabal: Funep, 2007. 576 p. 
GERALDO, J.; OLIVEIRA, L. D.; PEREIRA, M. B.; PIMENTEL, C. Fenologia e produção de massa seca e de grãos em cultivares de milheto-pérola. Pesquisa Agropecuária Brasileira, Brasília, v. 37, n. 9, p. 1263-1268, 2002. http://dx.doi.org/10.1590/S0100-204X2002000900009

GITTI, D. C.; ARF, O.; MELERO, M.; RODRIGUES, R. A. F.; TARSITANO, M. A. A. Influence of nitrogen fertilization and green manure on the economic feasibility of no-tilled wheat in the Cerrado. Revista Ceres, Uberlândia, v. 59, n. 2, p. 246-253, 2012. http://dx.doi.org/10.1590/S0034-737X2012000200014

INSTITUTO DE ECONOMIA AGRÍCOLA - IEA. Banco de dados: preços médios recebidos e pagos pelos produtores. Disponível em: <http://www.iea.sp.gov.br/out/index.php\#>. Acessado em: 20 fev 2012.

KANEKO, F. H.; ARF, O.; GITTI, D. C.; TARSITANO, M. A. A.; RAPASSI, R. M. A.; VILELA, R. G. Custos e rentabilidade do milho em função do manejo do solo e da adubação nitrogenada. Pesquisa Agropecuária Tropical, Goiânia, v. 40, n. 1, p. 102-109, 2010.

KAPPES, C. Coberturas vegetais, manejo do solo e doses de nitrogênio em cobertura na cultura do milho. 2012. 204 f. Tese (Doutorado em Sistemas de Produção) - Curso de Pós Graduação em Agronomia, Universidade Estadual Paulista, Ilha Solteira, 2012.

MATSUNAGA, M.; BEMELMANS, P. F.; TOLEDO, P. E. N.; DULLEY, R. D.; OKAWA, H.; PEDROSO, I.A. Metodologia de custo de produção utilizada pelo IEA. Agricultura em São Paulo, v. 23, p. 123-139, 1976.

OLIVEIRA, F. S.; ROCHA, M. R.; TEIXEIRA, R. A.; FALEIRO, V.O.; SOARES, R. A.B. Efeito de Sistemas de Cultivo no Manejo de Populações de Pratylenchus spp. na Cultura da Cana-de-Açúcar. Nematologia Brasileira, Piracicaba, v. 32, n. 2, p. 117-125, 2008.

RAIJ van, B.; CANTARELLA, H.; QUAGGIO, J. A.; FURLANI, A. M. C. Recomendações de adubação e calagem para o estado de São Paulo. In: RAIJ van, B.; CANTARELLA, H. (2 ed.rer.atual.). Milho para grãos e silagem. Campinas: Instituto Agronômico, 1997. p. 56-57.

SANTOS, H.P.; AMBROSI, I.; LHAMBY, J.C.B.; CARMO, C. Lucratividade e risco de sistemas de manejo de solo e de rotação e sucessão de culturas. Ciência Rural, Santa Maria, v. 34, n. 1, p. 97-103, 2004. http://dx.doi.org/10.1590/S0103-84782004000100015

SILVA, E. C.; MURAOKA, T.; MONTEIRO, R. O. C.; BUZETTI, S. Análise econômica da adubação nitrogenada no milho sob plantio direto em sucessão a plantas de cobertura em Latossolo Vermelho. Acta Scientiarum. Agronomy, Maringá, v. 29, n. 4, p. 445-452, 2007.

SILVA, D. A.; SOUZA, L. C. F. Análise econômica de sucessões de culturas para milho, com níveis de nitrogênio em cobertura. Revista Brasileira de Milho e Sorgo, Sete Lagoas, v. 6, n. 2, p. 256-262, 2007.

SILVA, E. C.; MURAOKA, T.; BUZETTI, S.; ESPINAL, F. S. C.; TRIVELIN, P. C. O. Utilização do nitrogênio da palha de milho e de adubos verdes pela cultura do milho. Revista Brasileira de Ciência do Solo, Viçosa, v. 32, p. 2853-2861, 2008.

SORATO, R. P.; SILVA, A. H.; CARDOSO, S. M.; MENDONÇA, C. G. Doses e fontes alternativas de nitrogênio no milho sob plantio direto em solo arenoso. Ciência e Agrotecnologia, Lavras, v. 35, n. 1, p. 6270, 2011. 